\title{
CLIMATIC INFORMATION FROM THE CHONGCE ICE CAP, WEST KUNLUN, CHINA
}

\author{
by
}

\author{
Masayoshi Nakawo
}

(Nagaoka Institute of Snow and Ice Studies, NRCDP, STA, Suyoshi, Nagaoka 940, Japan)

\author{
Yutaka Ageta
}

(Water Research Institute, Nagoya University, Nagoya 464-01, Japan)

and

Han Jiankang

(Lanzhou Institute of Glaciology and Geocryology, Academia Sinica, Lanzhou, China)

\section{ABSTRACT}

Shallow corings and pit studies were carried out in 1987 on the Chongce Ice Cap in the West Kunlun Mountains which lie along the southern edge of the Taklamakan Desert. Stratigraphic observations, as well as measurements of insoluble particles, chemical constituents and liquid conductivity, on the core and pit samples allowed identification of annual layers, although visible dirt layers are not always annual signals. A vertical profile of stable isotope content showed a periodic variation near the surface, strongly attenuated with depth.

\section{INTRODUCTION}

An important role of the Asian continent in the global climatic system has been recognized. The Xizang (Tibet) Plateau has been considered to be an elevated heat source which contributes to seasonal reversal of air circulation (Luo and Yanai, 1983; 1984; He and others, 1987). Also, Eurasian snow cover was found to have a close correlation with the strength of Indian monsoon rainfall (Hahn and Shukla, 1976). It was further suggested that the El Nino-Southern Oscillation phenomenon was intimately associated with the snow cover in Asia (Yasunari, 1987; Barnett and others, 1988). The role of the plateau is of great importance to the global climate.

Meteorological data for the plateau, however, are very few. Climatic information may be obtained by analyzing ice-core samples from many glaciers and ice caps in the area (Thompson and others, 1988).

\section{FIELD ACTIVITY}

The West Kunlun Mountains are located on the northwestern edge of the Tibetan Plateau (Fig. 1). The Chongce Ice Cap in these mountains extends over a distance of about $7 \mathrm{~km}$, having two noticeable peaks $6530 \mathrm{~m}$ and $6374 \mathrm{~m}$ high (Fig. 2). The elevation of the terminus is about $5800 \mathrm{~m}$. Average thickness, measured by a pulse modulation radar, was about $70 \mathrm{~m}$ near the lower peak and $100-150 \mathrm{~m}$ around the midstream of the ice cap (Zhu, 1989).

Pit studies were made at seven sites, A3, A5, B4, B8, B8' (adjacent to B8), B12 and B13 for stratigraphic observations and for sampling (Ageta and others, 1989). Shallow cores of $10 \mathrm{~m}, 23 \mathrm{~m}$ and $32 \mathrm{~m}$ were obtained at B13, B12, and B8 respectively (Nakawo and others, 1989).

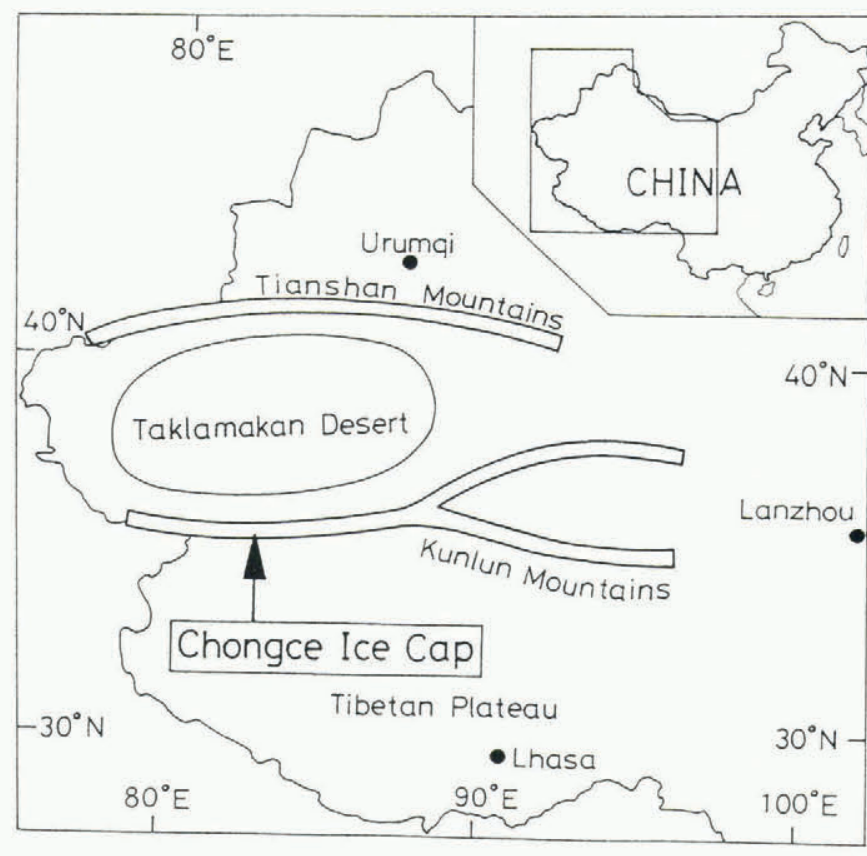

Fig. 1. Locations of the Chongce Ice Cap (lat. $35^{\circ} 14^{\prime} \mathrm{N}$; long. $81^{\circ} 07^{\prime} \mathrm{E}$ ) in the West Kunlun Mountains.

Snow and ice samples from the pits and the cores were mostly melted in situ and shipped for further analyses.

\section{RESULTS}

The stratigraphy, oxygen-isotope content, liquid conductivity, and solid particle content are shown in Figure 3 for snow or ice layers near the surface deposited in two years (July 1985-August 1987), identified by snow-stake measurements, at A5 during the period. Particle contents are presented as weights of particles of a diameter larger than $5 \mu \mathrm{m}$, collected through filtering. The surface layer consisted mostly of firn layers with relatively thin ice layers in between. Three horizontal dirt bands were visibly identified as shown in the figure. Two peaks can be seen in the $\delta^{18} \mathrm{O}$ profile with minimum values at around depths of $0,0.5$ and $0.8 \mathrm{~m}$, although the amplitude decreased with depth. Also, 


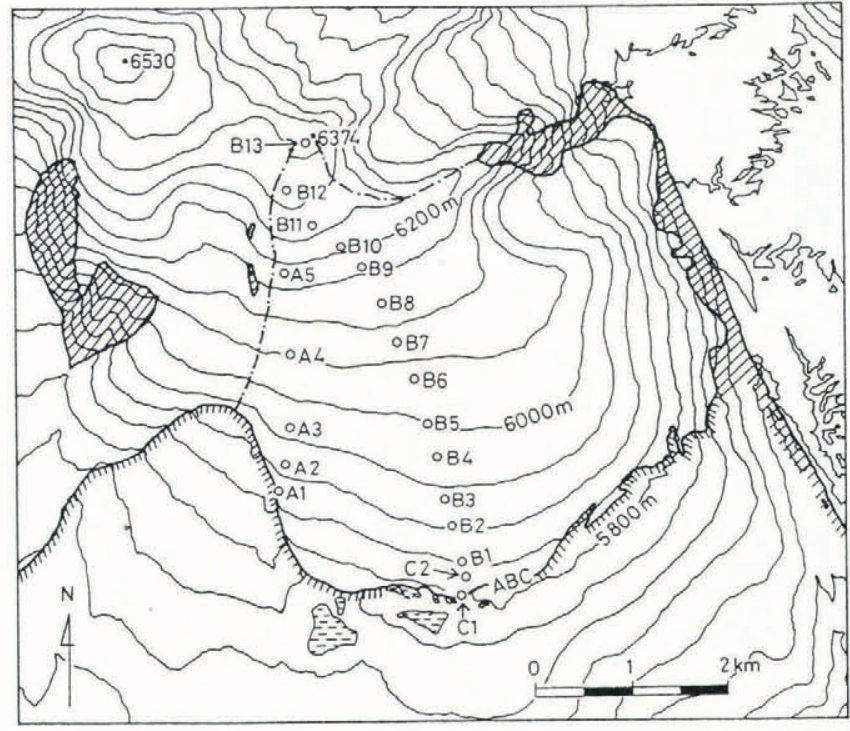

Fig. 2. The Chongce Ice Cap and the observation sites. ABC: Advance Base Camp (after Chen and others, 1989).

there are cyclic variations with a period of about $0.4 \mathrm{~m}$ in both conductivity and solid particle content, with an additional conductivity peak at about $0.6 \mathrm{~m}$.

The values of $\delta^{18} \mathrm{O}$ for summer precipitation of newly deposited surface snow in 1989 were about -2 to $-10 \%$, larger than average $\delta$ values for glacier ice or values for glacier run-off water, which would roughly equal the annual average. This indicates that winter precipitation should show a smaller $\delta$ value than summer. The relatively low values in the $\delta$ profile in Figure 3 , at around 0.5 and $0.8 \mathrm{~m}$, hence, would correspond to winter layers, since the $0.8 \mathrm{~m}$ thick layer covered two full years.

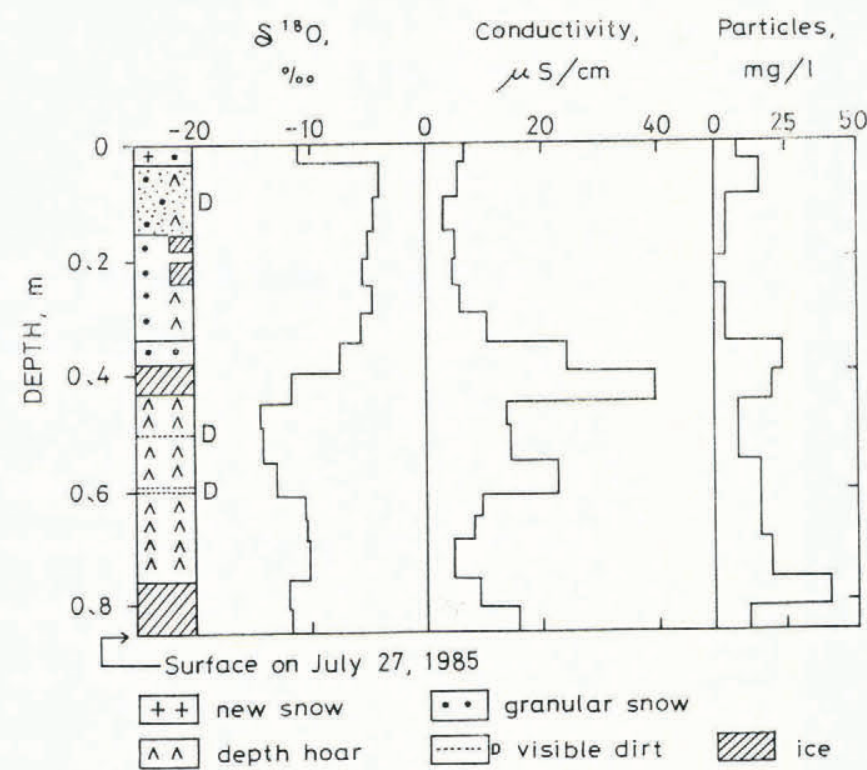

Fig. 3. Stratigraphy, $\delta^{18} \mathrm{O}$, liquid conductivity and particle content (given in weight of particles larger than $5 \mu \mathrm{m}$ ) in the two full year layer (July 1985 to August 1987) at A5 (6180 m a.s.l.).

Year-round precipitation data are not available at the West Kunlun Mountains. At meteorological and hydrological stations around the mountains, it has been shown that precipitation takes place mostly in the warm season (May to September), with drought from fall to spring (Kang and $\mathrm{Xie}, 1989)$. The layers with relatively large $\delta$ values (summer) are much thicker than those with small $\delta$ values (Fig. 3): the summer balance is larger than the winter balance on the ice cap. Relatively high conductivity seems to be associated with the layer formed in the dry season. High concentration of particles or dirt layers would also form in winter when the precipitation is poor. These are

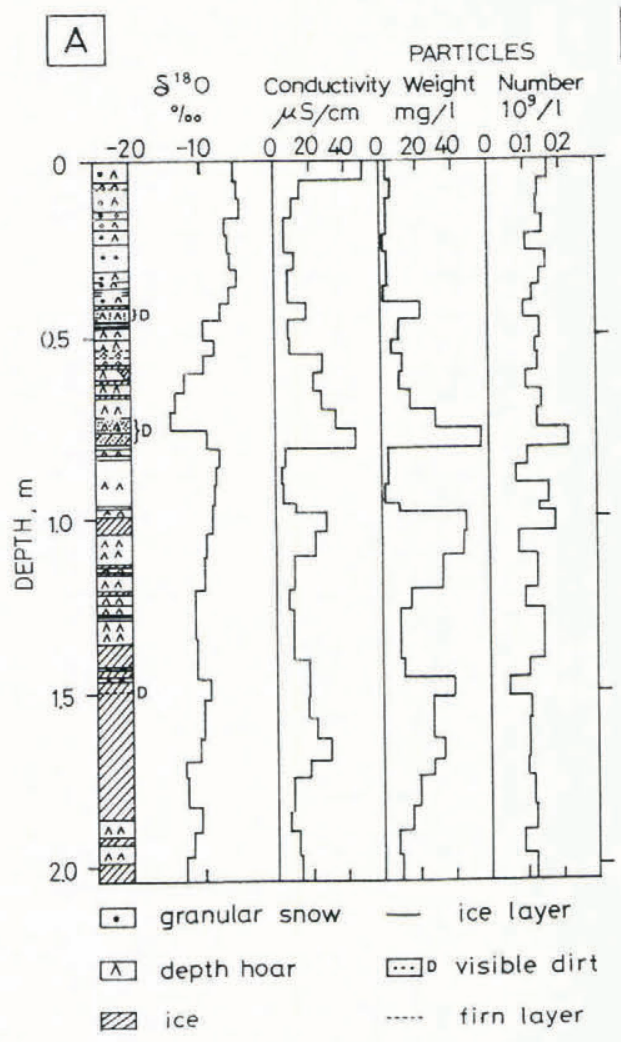

B

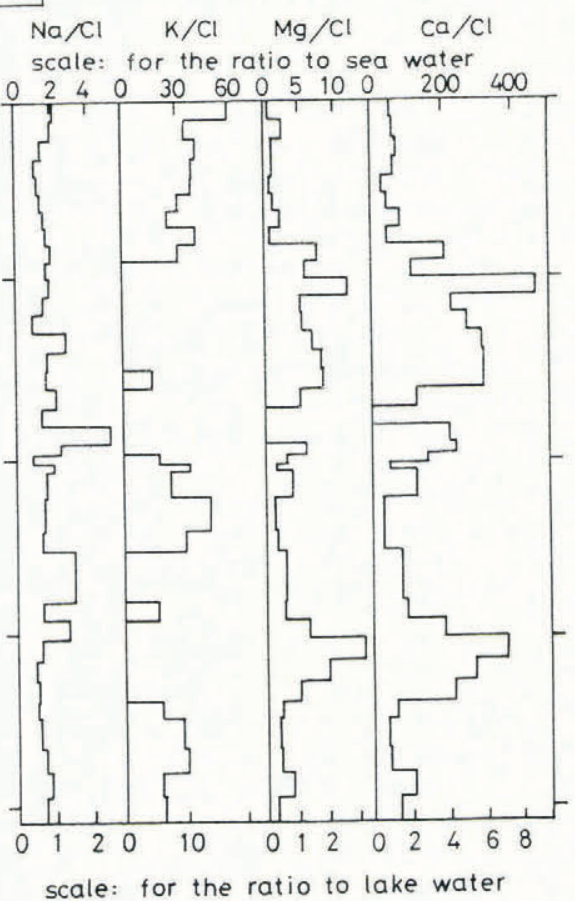

Fig. 4. Characteristics of surface snow/ice layer at B13 (6366 ma.s.l.) near the summit of the lower peak of the ice cap. (a): Stratigraphy, $\delta^{18} \mathrm{O}$, liquid conductivity, and particle content (given in weight of particles larger than $5 \mu \mathrm{m}$ and in number of microparticles $(1<\phi<5 \mu \mathrm{m})$ ). (b): Cations ratio to chlorine. The scale at the top is for the ratio to sea water, and the bottom scale is for the ratio to lake water. 
encouraging, since annual layers would possibly be identified by analyzing $\delta^{18} \mathrm{O}$, conductivity and particle content.

Figure $4 \mathrm{a}$ shows profiles of these variables at B13, around the lower peak of the ice cap (Fig. 2). Particle content is given by the weight of large particles, and by the number of micro-particles of diameter smaller than $5 \mu \mathrm{m}$. The variation of $\delta^{18} \mathrm{O}$ becomes less intense with increasing depth, and no periodic change can be found at greater depths where continuous ice layers exist. This is probably due to the homogenization of the heavy isotope caused by the refreezing of melt water in the surface snow/ firn layer.

Profiles of conductivity and large particle content are very similar to each other (Fig. 4a). Three peaks appear in each curve, indicating the depths of winter layers, as discussed above, even at the greatest depth where no noticeable peaks were found in the $\delta$ curve. It should be noted that the locations of peaks of particle content are not always compatible with the site of visible dirt bands, although Thompson and others (1988) reported the existence of annual dust layers in the Dunde Ice Cap, Qilian Shan, China.

Figure $4 \mathrm{~b}$ shows variations of cations at the same spot. The upper scale gives the ratio of each cation to $\mathrm{Cl}$ divided by the ratio to $\mathrm{Cl}$ in sea water. The lower scale is the ratio to $\mathrm{Cl}$ with the reference of lake water around the mountains (Fushimi and others, 1988). Figure 4b seems to suggest that precipitation in the mountains could be mostly of local origin, i.e. from evaporation in and around the area (Nakawo and Takahara, 1988), since the ratio of the cations to $\mathrm{Cl}$ in the core samples is very close to the ratio found in lake waters.

The profiles of $\mathrm{Mg}$ and $\mathrm{Ca}$ are very similar to each other; three noticeable peaks are found at the same depths where conductivity and particle content exhibited maxima. It is interesting to note that the variation of $\mathrm{K}$ is inversely correlated with the change of $\mathrm{Mg}$ and $\mathrm{Ca}$ : peaks in $\mathrm{K}$ profile are found at depths where minimum values are obtained for $\mathrm{Mg}$ and $\mathrm{Ca}$, and vice versa. In other words, $\mathrm{Mg}$ and $\mathrm{Ca}$ increase in winter and decrease in summer, while $\mathrm{K}$ decreases in winter and increases in summer. It is considered, therefore, that analyses of these cations would also enable us to estimate annual layers, and hence the climatic history around the area.

\section{ACKNOWLEDGEMENTS}

The analyses of cations and micro-particle content were carried out at the National Institute of Polar Research, for which the authors are grateful to Dr. Y. Fujii. Field activities were financially supported by the Monbusho International Scientific Research Programme (No. 62041043,
63043030). Laboratory analyses were supported by the Special Coordination Funds for Promoting Science and Technology.

\section{REFERENCES}

Ageta, Y., Zhang Wenjing, and M. Nakawo. 1989. Mass balance studies on Chongce Ice Cap in the West Kunlun Mountains. Bull. Glacier Res., 7, 37-43.

Barnett, T.P., L. Dümenil, U. Schlese, and E. Roecker. 1988. The effect of Eurasian snow cover on global climate. Science, 239(4839), 504-507.

Chen Jianming, Wang Yan, Liu Lansheng, and Gu Pei. 1989. Surveying and mapping on Chongce Ice Cap in the West Kunlun Mountains. Bull. Glacier Res., 7, 1-5.

Fushimi, H., K. Kamiyama, Y. Aoki, Zheng Benxing, Jiao Keqin, and Li Shijie. 1989. Preliminary study on water quality of lakes and rivers on the Xizang (Tibet) Plateau. Bull. Glacier Res., 7, 129-137.

Hahn, D.G. and J. Shukla. 1976. An apparent relationship between Eurasian snow cover and Indian monsoon rainfall. J. Atmos. Sci., 33, 2461-2462.

He, H., J. McGinnis, Z. Song, and M. Yanai. 1987. Onset of the Asian summer monsoon in 1979 and the effect of the Tibetan Plateau. Mon. Weather Rev., 115, 1966-1995.

Kang Xingcheng and Xie Yingqin. 1989. The character of the weather and climate in the West Kunlun Mountains area in summer, 1987. Bull. Glacier Res, 7, 77-81.

Luo, H. and M. Yanai. 1983. The large-scale circulation and heat sources over the Tibetan Plateau and surrounding areas during the early summer of 1979. Part I. Precipitation and kinematic analyses. Mon. Weather Rev., 111, 922-944.

Luo, H. and M. Yanai. 1984. The large-scale circulation and heat sources over the Tibetan Plateau and surrounding areas during the early summer of 1979. Part II. Heat and moisture budgets. Mon. Weather Rev., 112, 966-989.

Nakawo, M. and H. Takahara. 1988. Evaporation of river water in West Kunlun Mountains, China. Bull. Glacier Res., 6, 9-15.

Nakawo, M., Y. Nakayama, S. Kohshima, T. Nishimura, Han Jiankang, and Zhou Tao. 1989. Ice coring operation at high altitudes in West Kunlun Mountains, China. Bull. Glacier Res., 7, 15-19.

Thompson, L.G., Wu Xiaoling, E. Mosley-Thompson, and Xie Zichu. 1988. Climatic records from the Dunde Ice Cap, China. Ann. Glaciol., 10, 178-182.

Yasunari, T. 1987. Global structure of the El Niño/Southern Oscillation. Part II. Time evolution. Journal of Meteorological Society of Japan, 65, 81-102.

Zhu Guocai. 1989. Ice thickness and subglacial topography obtained by radar sounding on Chongce Ice Cap, West Kunlun Mountains. Bull. Glacier Res., 7, 7-14. 